\title{
NEIGHBORHOOD EFFECTS OF DEVELOPING COUNTRY PROTECTION
}

\author{
Alan V. DEARDORFF and Robert M. STERN* \\ The University of Michigan, Ann Arbor, MI 48109, USA
}

Received April 1985, final version received September 1985

\begin{abstract}
We examine how protection in LDCs affects welfare in other countries whose economic circumstances are similar. Theoretical analysis suggests the effects may be positive or negative. Analysis of data on protection in nine selected LDCs showed positive correlations among patterns of protection and trade, but a tendency for greater protection against the exports of other LDCs than against developed countries. To evaluate the general equilibrium economic effects involved, we used the Michigan Computational Model of World Production and Trade. The results showed positive terms-of-trade effects on other countries within the LDC sample group and negative effects for may DCs. However, the terms-of-trade improvement was very small and cannot be expected to outweigh the efficiency losses of protection within the LDCs themselves.
\end{abstract}

\section{Introduction}

Analyses of tariffs and other forms of protection have focused mainly on their effects on the protecting country. In two-country models there has been some attention to effects on the other country, but this is equivalent to looking at effects on the rest of the world as a whole. Except in the customs union literature where the issues in any case are different, there has been little attention to the effects that a country's protection may have on individual foreign countries that make up only a part of the rest of the world. In this paper we address this issue, looking specifically at the effects that levels of protection in developing countries may have on other countries in their economic 'neighborhood' - that is, countries whose economic circumstances are similar to their own.

The issue is potentially of great importance. The successes of some developing countries in recent years, together with the overall growth of populations even in the less successful ones, have expanded their importance

\footnotetext{
*The research underlying this paper was supported by grants from the Bureau of International Labor Affairs of the U.S. Department of Labor and the Ford Foundation. We are grateful to Deborah Laren and Malcolm Robinson for computational assistance.
} 
in international trade. ${ }^{1}$ In addition, empirical evidence suggests that there has been a noteworthy increase in intra-LDC trade, in manufactures especially. Yet most LDCs have remained outside the international negotiating framework that has reduced tariffs among developed countries. In addition, LDCs have always made extensive use of non-tariff barriers (NTBs), and these too restrict the access of international trade to their markets. The question then arises whether all of this LDC protection, in addition to having the own-country effects that have long been familiar in the tariff literature, have additional adverse or beneficial consequences for LDCs as a group when one takes into account these neighborhood effects.

To examine this issue, we introduce a simple theoretical framework in section 2 in which three countries produce and trade three goods, and the effect of one's tariffs on another depends on the particular patterns of specialization and trade that occur. It is seen that one country's tariff may have either beneficial or harmful effects on other particular countries, depending essentially on whether the other country's pattern of trade and protection is similar to its own.

Since our theoretical analysis suggests that the neighborhood effects of protection may be either positive or negative, we turn in the remainder of the paper to empirical analysis of the issue. We base this empirical analysis on a sample of data on protection in nine developing countries, which we call the 'focus countries'. While these particular data are neither very recent, nor at all comprehensive, they still may be representative of the patterns of protection that exist in LDCs. Also, since the data for some of the focus countries implicitly include effects of NTBs, our analysis is suggestive of the effects of these as well. In section 3 we introduce and explain how we have adapted the data for comparability.

In section 4 we analyze what these data imply about the neighborhood effects of protection by means of correlations, both among the protection levels themselves and among trade patterns for the countries involved. Then we look at the different implications of these levels of protection for other LDCs and for selected developed countries as well, by calculating various weighted averages of protection that are relevant for the different trading partners.

The problem with looking just at the data themselves is that they are indicative of the most direct effects that protection may have and cannot even begin to capture the host of indirect effects that may occur in a general equilibrium system. A complete analysis thus requires an explicit general

\footnotetext{
${ }^{1}$ For example, considering only the 16 LDCs that are included in the Michigan model which we will be reporting on below, these countries accounted for over half of the world's total employment and more than 10 percent of world output and trade in 1976. Thus while individually most of them are very small, collectively they bulk as large in world markets as almost any of the larger developed countries.
} 
equilibrium model, and we therefore devote the remainder of the paper to an analysis of neighborhood effects of protection using the Michigan computable model of world production and trade.

The model itself is described only briefly in section 5 , since it has been extensively documented elsewhere. Then in section 6 we report the results of using the model to calculate the effects of the developing country protection levels introduced in section 3. Since our theoretical analysis in section 2 turned heavily on the terms-of-trade effects of protection, we concentrate on our model's calculations of changes in the terms of trade of various countries due to the focus countries' levels of protection. We conclude in section 7 , summarizing our results, but also noting some reservations that we have concerning them.

\section{Theoretical considerations}

The effects of one country's protection on the welfare of another depend solely on the price effects involved. The benefit that a country derives from trade depends on the world prices at which it trades and on the efficiency with which its producers and consumers respond to those prices. The latter can be reduced by the country's own trade policies, but not by the policies of other countries. ${ }^{2}$ Since such foreign policies affect a country only through their effects on world prices, what we are really talking about are terms-oftrade effects. That is, protection in one country improves welfare in another to the extent that it raises the price of the latter's exports relative to its imports.

In a two country model, there is a strong presumption in one direction concerning the effects of a tariff on the terms of trade. Barring exceptional circumstances, a tariff reduces a country's demand for imports and also, after various general equilibrium adjustments, its supply of exports. Both changes work in the direction of raising the world price of its exports relative to its imports. In a two country model, since each country's exports are the other's imports, a country's tariff thus worsens the terms of trade of its (only) trading partner. There are numerous exceptions to this result in the trade theory literature, but interest in them derives largely from the fact that they are indeed exceptional. We will not be concerned accordingly with these exceptions and will assume instead that protection tends to improve the terms of trade of the protecting country.

In a world of more than two countries, however, the effect on the terms of trade of the protecting country tells little about the effect on any individual country elsewhere in the world. It is possible, in general, that some countries

\footnotetext{
${ }^{2}$ This may seem to assume that the revenues or rents due to protection are captured solely within the protecting country, ruling out such policies as voluntary export restraints (VERs), but this is not the case. VERs generate rents for exporters precisely because of higher export prices.
} 
share exactly the same trading pattern as the protecting country itself, and, if so, then these countries share in the improvement of the protecting country's terms of trade. This could obviously not be true of all other countries in the world, but it could be true of a large enough number of countries to be important. In particular, if we focus on countries at a similar stage of development, that very similarity may well suggest similarity in trade pattern. This might therefore lead to a presumption that the neighborhood effects of protection, as we use the term here, would be positive.

To see these possibilities more clearly, consider a model of three countries, $A, B$, and $\mathrm{C}$, producing and trading three goods, $X, Y$, and $Z$. Suppose that, aside from its dimensionality, the model satisfies the conventional assumptions of the Heckscher-Ohlin model of international trade. That is, production functions display constant returns to scale, all markets are perfectly competitive, and so on. Let there be two factors of production, capital and labor, from which all three goods are produced, and assume that factor prices are not equalized internationally. ${ }^{3}$ It follows that prior to protection countries are completely specialized in production, in this case meaning that no two countries produce more than one good in common. What happens when protection is introduced, then, depends on what the particular pattern of specialization happens to be.

Two such patterns suffice to illustrate the possibilities, and are shown in fig. 1, panels (a) and (b). Regarding factor endowments, suppose that country $A$ is the most developed of the three countries and country $C$ the least, as measured by their ratios of capital to labor. Suppose also that good $X$ is the most capital intensive in its production, while good $Z$ is the least.

The one possibility, if the two LDCs are relatively small in terms of their total capacities to produce, is that both will specialize in producing the least capital intensive good, $Z$, and will export it to $A$ in exchange for both $X$ and $Y$. This is the pattern of specialization shown in fig. 1a, where the crosses indicate which goods are produced, and therefore exported, by each country.

A second possibility is shown in fig. 1b. Here, the LDCs, B and C, are somewhat larger (or perhaps the world demands for $Y$ and $Z$ are smaller) so that together they can satisfy world demands for both $Y$ and $Z$. However, because of the assumption that factor prices are not equalized, both countries will not produce both goods, and we have selected instead the case in which each produces only one. In accordance with the Heckscher-Ohlin theorem, we have the least capital-abundant country, $C$, specializing in the least capital-intensive good, $Z$. Clearly, many other patterns of specialization are possible, including those in which particular goods are produced in more

\footnotetext{
${ }^{3}$ As is well known, factor prices would be equalized in such a model if trade were perfectly free and if countries' factor endowments were not too diverse. In dealing with the wide range of developed and developing countries, we find these assumptions implausible and, following Krueger (1977) and Deardorff (1979), prefer to assume internationally unequal factor prices.
} 


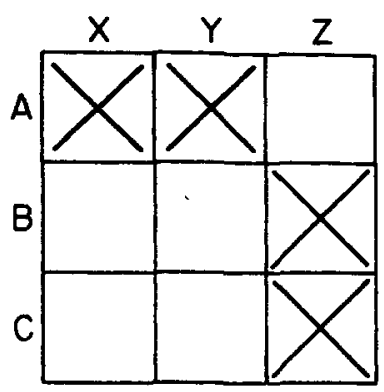

(a)

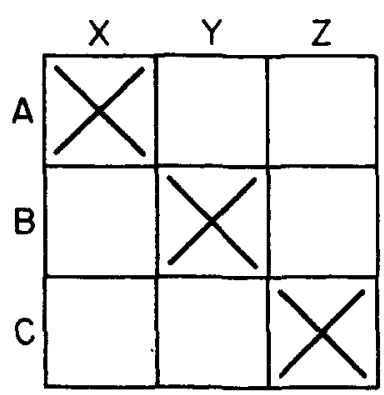

(b)

Fig. 1. Patterns of specialization. Countries are ranked by state of development, with $A$ highest and $C$ lowest. Goods are ranked by capital intensity, with $X$ highest and $Z$ lowest. The crosses indicate patterns of specialization and exports.

than one country. But the two patterns in fig. 1 serve well to indicate what will happen when protection is introduced, since the patterns of trade, as well as specialization, are evident.

What then happens when one of the LDCs, say country C, introduces a tariff, and what in particular is the effect on its economic 'neighbor', country B?

In case (a) the answer is likely to be unambiguous, but is opposite to that alluded to above for the two country model. Since both B and C export $Z$ and import $X$ and $Y$, an improvement in the protecting country's terms of trade will also benefit its neighbor. That is, when $C$ levies tariffs on $X$ and/or $Y$, its demand for one or both of these goods will be reduced. Also, it will now offer less of its export good, $Z$, in exchange for what it imports, and this will reduce the supply of $Z$ on the world market. Thus the price of $Z$ relative to $X$ and $Y$ will tend to rise. This is not absolutely necessary, but as noted above, we will assume that protection always improves the protecting country's terms of trade. In this case, since $B$ and $C$ share qualitatively identical trade patterns, price changes that improve the terms of trade for $\mathrm{C}$ will also tend to do so for $B$. Thus here the neighborhood effects of protection are most likely positive. ${ }^{4}$

\footnotetext{
${ }^{4}$ Again this is not absolutely necessary. If $\mathrm{B}$ and $\mathrm{C}$ have different preferences and thus import $X$ and $Y$ in different proportions, then other outcomes are possible in special circumstances. For example, a tariff on only $X$, if $X$ and $Y$ are close substitutes in C, could merely shift demand toward $Y$ and raise its price. If $B$ has a strong preference for $Y$ and imports a great deal of it, this price change would worsen its terms of trade.
} 
In case (b), on the other hand, the result depends crucially on which of its imports country $\mathrm{C}$ chooses to protect. If it protects good $X$, which both it and country B import from A, then as in case (a) this will lower world demand for $X$, lower its price, and improve the terms of trade of both LDCs. But if it protects instead good $Y$, which it imports from B, then it is good $Y$ whose price will fall and country B clearly loses. In general, if $\mathrm{C}$ protects both $X$ and $Y$, then the effect on B's terms of trade is ambiguous, depending on the sizes of protection of the two goods, plus various elasticities of supply and demand and the initial quantities traded.

Thus, the neighborhood effects of protection, unlike their effects on the rest of the world as a whole, can easily be either positive or negative, depending on the particular patterns of trade that prevail and perhaps also on other parameters of behavior. The result cannot be predicted clearly and simply in theoretical terms, ${ }^{5}$ and must be examined in the context of a model in which all these factors can be made explicit and based on empirical observations. Thus it is a natural problem to address using a computable general equilibrium model of trade and protection. This will lead us, later in the paper, to use the Michigan model for this purpose. First, however, we will examine our data directly to see if they offer any clues as to which of the possible outcomes is most likely.

\section{Sample data on developing country protection}

We have been working for some time to assemble, and assimilate into a computerized data base, a mass of published information regarding tariffs and NTBs around the world. ${ }^{6}$ While our effort is still incomplete, we have used the facility being developed to process a sample of data for use in this paper. From a variety of sources, we have data on protection in several LDCs. Since, because of their diverse sources, these data are reported for different industry classification schemes, we have used our computer facility to concord all of them into the classification system used in the Michigan model. ${ }^{7}$ The results of the procedure are reported in table 1.

\footnotetext{
${ }^{5}$ It is not difficult to add more countries to the same theoretical framework. Thus, depending upon the number and size of countries and whether their protection is coordinated or not, their terms of trade may improve or decline with protection.

${ }^{6}$ Our ongoing efforts also include an annotated bibliography of the literature dealing with the theoretical analysis and empirical measurement and effects of NTBs.

${ }^{7}$ Using the published industry and product names, we constructed concordances from each classification system used in the sources to 4-digit ISIC - International Standard Industrial Classification - categories. The published tariff and NTB data were mapped via these concordances and then averaged up to the 1- and 3-digit ISIC categories of the Michigan model using the respective countries' imports as weights. Import data were taken from 1976 United Nations trade tapes.
} 


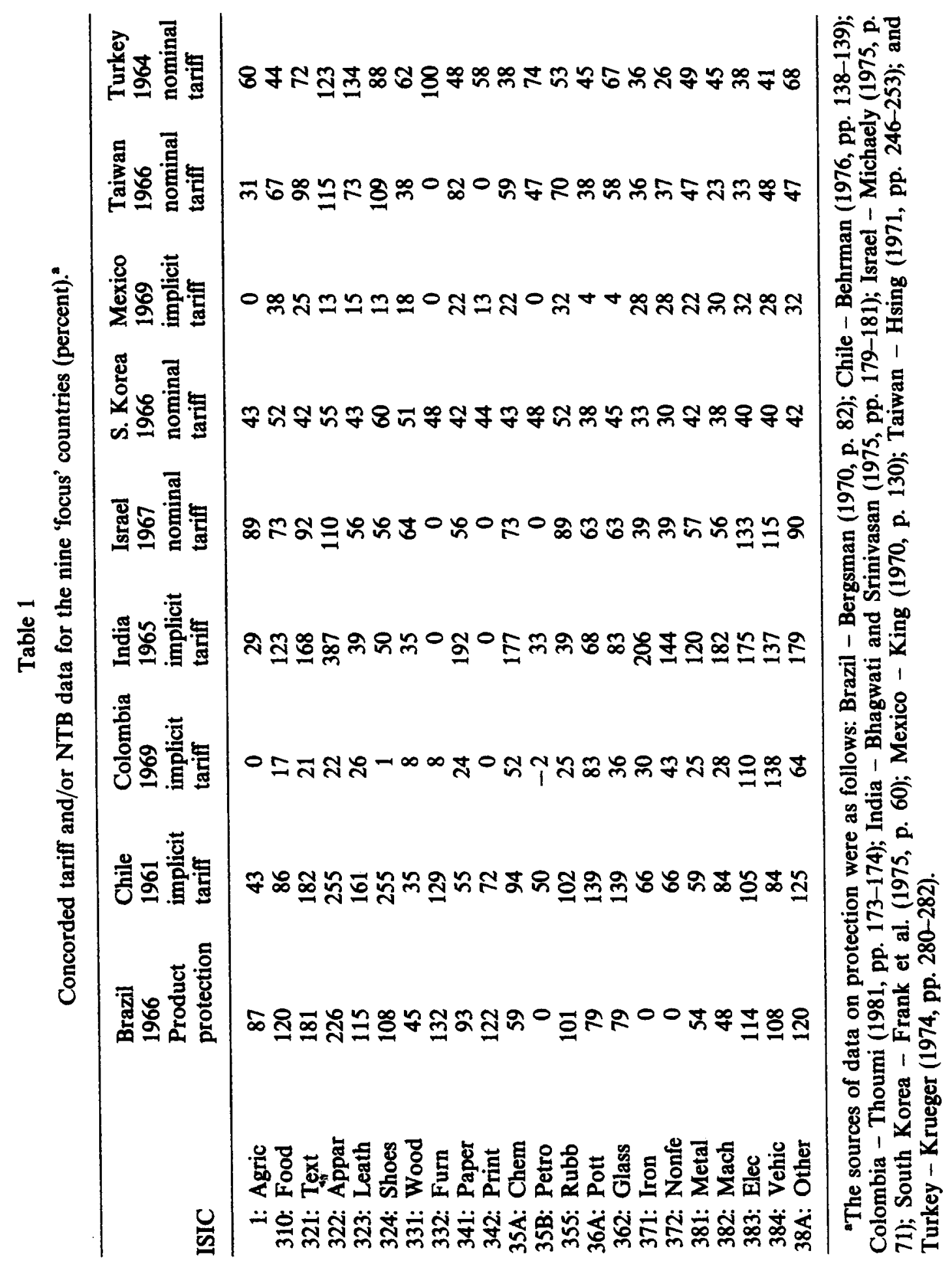


As can be seen, our data cover nine developing countries, which we call the 'focus' countries, for a variety of years during the $1960 \mathrm{~s}^{8}$ The focus countries have been chosen from the group of 16 newly industrializing countries (NICs) which are included in the Michigan model. As indicated, some of the data refer only to nominal tariffs. In other cases, we have reports of 'implicit' tariffs that attempt to include the ad valorem equivalents of NTBs, as inferred from comparisons of domestic and international prices. ${ }^{9}$ In addition, for Brazil, we have something called 'product protection', in which nominal tariffs have been augmented by explicit measures of certain NTBs that were available, such as exchange premia, port charges, etc.

These data are of course rather old, and they differ considerably among themselves in the extent to which they include NTBs in their coverage. Still, they provide a useful glimpse of how LDC protection can vary across industries and countries, and therefore a starting point for an analysis of how protection in these countries affects one another.

It is clear from these data that protection was substantial, and also that in most of the countries it varied greatly across sectors. Thus there is considerable scope for these levels of protection to have differential effects across industries that could in turn show up as terms-of-trade effects of the sort discussed above. Before using the Michigan model to calculate such terms-of-trade effects, however, we shall undertake a direct analysis of the data themselves.

\section{Direct comparison of protection}

We saw that a country's structure of protection might benefit another country to the extent that the two countries share similar patterns of both trade and protection. In table 2 we report correlations that attempt to gauge this similarity. The table has three panels, the first of which reports a matrix of correlations between each pair of the nine columns of table 1 . The second and third panels report similar correlations among vectors of export shares and import shares.

Looking first at the correlations among levels of protection, more of these are positive than negative. Of the eight possible correlations that can be reported for each of the nine focus countries, only Turkey has four positive and four negative, and even here the positive correlations tend to be the larger. At the other extreme is Brazil, whose levels of protection are positively correlated with protection in each of the other eight countries. All of this gives some weak indication that protection in the countries might spill over positively in terms of its effects on the others in the group.

\footnotetext{
${ }^{8} \mathrm{We}$ are currently in the process of gathering more recent information on protection in DCs and LDCs to be incorporated into our data base. Details are available on request.

${ }^{9}$ See Deardorff and Stern (1985c) for a critical appraisal of this method of measuring NTBs.
} 


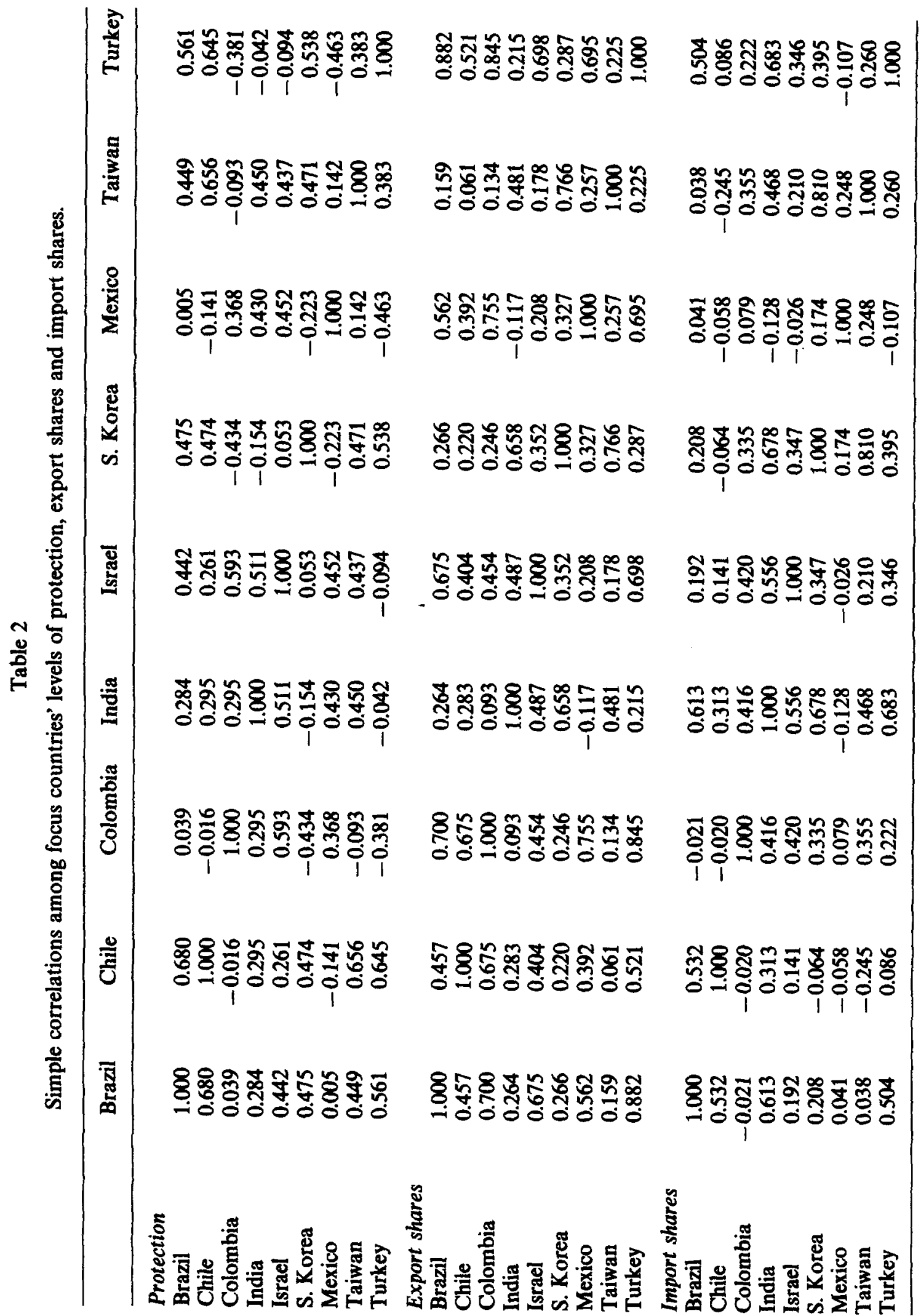


This impression becomes stronger when we look at the correlations among trade shares in the next two panels of table 2 , in which we have correlated vectors of exports as a share of industry domestic production and vectors of imports as a share of industry domestic demand. ${ }^{10}$ Again, especially for the export shares, the correlations are largely positive. Thus it seems likely that if one country's protection raises the world prices of its exports and/or lowers the world prices of its imports, the others in the group will share in the benefit.

These results, however, deal only with comparisons among levels of protection alone and among levels of trade alone. They do not get at the equally important question of how one country's protection compares to another's trade. That is, are these countries' tariffs and other forms of protection biased towards or away from the exports of their neighbors? We try to answer this question in table 3.

Here we report various export-weighted averages of each country's levels of protection from table 1. For example, in column one of table 3, Brazil's measures of 'product protection' have been averaged. The first average uses Chile's exports as weights and yields an average level of product protection of only 25 percent. This is quite small, as a result of Brazil's zero level of protection reported for non-ferrous metals, which is the industry where Chile happens to concentrate the bulk of its exports. In contrast, Brazil's average level of protection using Colombia's exports as weights is much larger, 96 percent. Colombia, evidently, exports a higher proportion of the goods that Brazil protects. Indeed, this average is even higher in other countries, reaching a high of 127 percent using South Korean exports as weights.

Further down in table 3, averages are reported that use exports of certain developed countries (DCs) and regions as weights. What is most interesting here, perhaps, is the comparison of the average based on all sixteen LDCs' exports versus that based on all eighteen DCs. For six of the nine focus countries, protection against LDC exports is larger than against DC exports. The difference is quite noticeable in the cases of Brazil and Chile, and also Taiwan and Turkey. In only three countries, Colombia, India and Mexico, is protection lower against other LDCs, and of these the difference is marked only in Colombia.

Thus, these averages of protection in table 3 tell a different story than the simple correlations in table 2 . Several countries seem to protect more heavily against the exports of their LDC neighbors than they do against the exports of developed countries. This suggests therefore that the erection of these trade barriers should have worsened the terms of trade of their neighbors, and thus that the neighborhood effects of their protection would be negative.

\footnotetext{
${ }^{10}$ We used these shares instead of total trade to avoid misleading correlations that could result from similarities of industry size.
} 


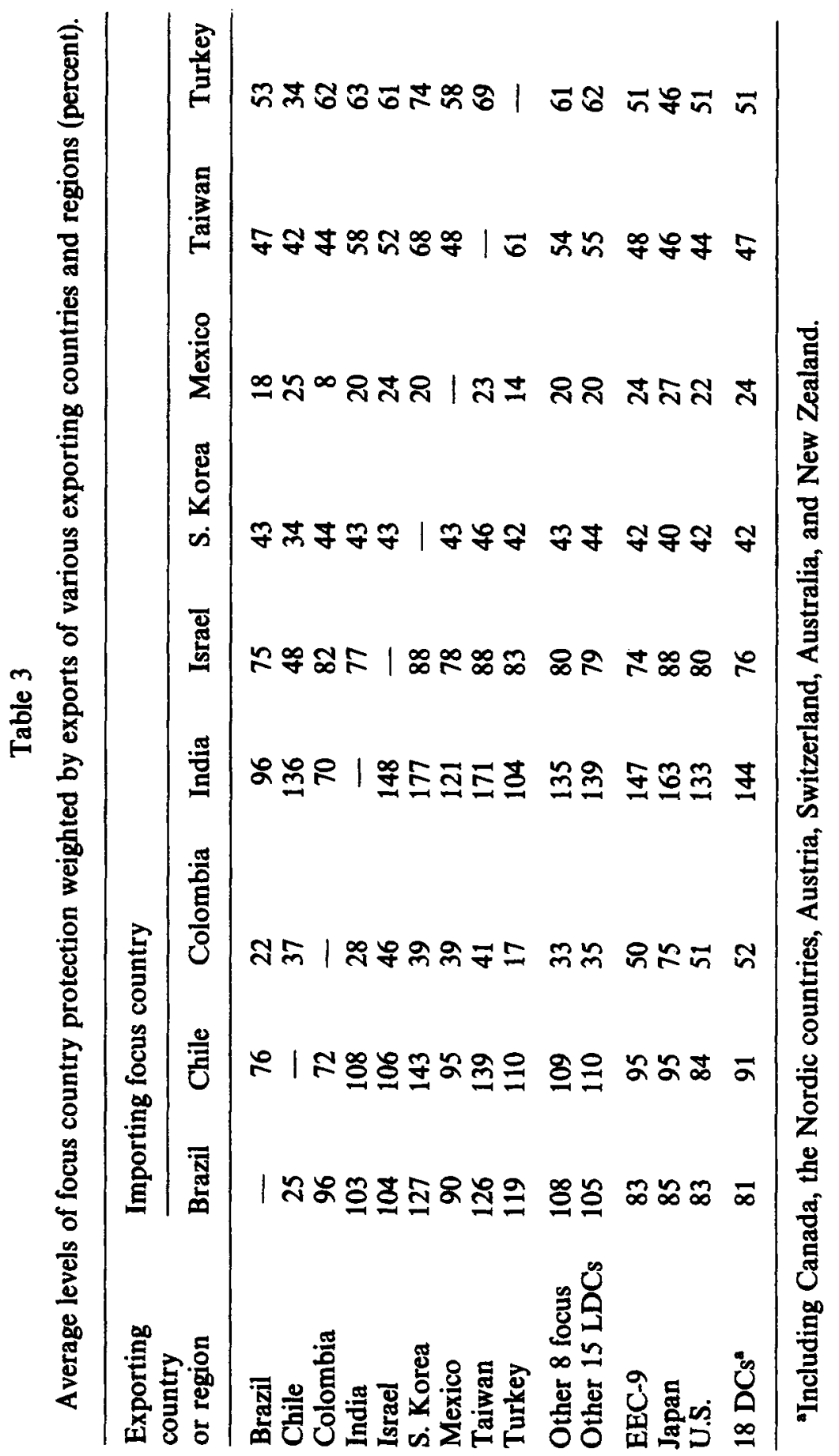


Together, then, these pieces of evidence derived from direct examination of the data on trade and protection leave a mixed impression. It is unclear what to expect from the more elaborate analysis to come. This is just as well, perhaps, since we would have reason to doubt the message of such simple comparisons as these in any case, given the complications that we know can be introduced by the sorts of general equilibrium interactions that are accounted for in the Michigan model.

\section{Description of the Michigan model and its application}

The Michigan model of world production and trade is well suited to the analysis of the issues in this paper. It was developed originally to analyze the economic effects of the Tokyo Round, and we have since used it for a variety of other issues. ${ }^{11}$ Space does not permit a full presentation and discussion of the model, but a brief description may nonetheless be useful. ${ }^{12}$

The model incorporates supply and demand functions and market-clearing conditions for the 29 industries and 34 countries listed in table 4. National and world markets determine equilibrium prices and quantities traded and produced, plus the flexible exchange rates. Labor-demand functions also determine employment in each industry and country. We abstract from such macroeconomic determinants of aggregate employment as levels of government spending, taxes and the money stock. Instead, nominal wages are held fixed and aggregate expenditure is adjusted endogenously to stabilize aggregate employment in each country.

Supply and demand functions were derived from maximization of profit and utility functions. These in turn were selected so as to permit a rich variety of behavior, but also to have parameters that could be either readily observed from available data or inferred from published econometric estimates. The current model uses a base of 1976 data on trade, production, and employment. To describe technology, we use the 1972 input-output table for the U.S. and the 1970 national tables for the individual EECmember countries, Japan, and Brazil. The remaining industrialized and developing countries are described by the U.S. and Brazilian tables respectively. ${ }^{13}$ Estimates of import-demand elasticities and elasticities of capitallabor substitution were obtained from the literature. ${ }^{14}$

\footnotetext{
${ }^{11}$ See Deardorff and Stern (1986) for details on these various applications of the model.

${ }^{12}$ The model is presented in detail in Deardorff and Stern $(1981,1986)$.

${ }^{13}$ This use of one country's I-O table to describe technology in another is a drawback imposed by current limitations in our available data. We have examined the significance of using different $\mathrm{I}-\mathrm{O}$ tables in the model in Deardorff and Stern (1985b).

${ }^{14}$ With one exception, supply elasticities for both export and domestic sales are derived from the asssumed production functions using these estimates of capital-labor substitution, together with labor and value-added shares from the input-output tables. The exception is the petroleum and related products industry, ISIC 35B, where on that basis the supply elasticity would be
} 
Table 4

Countries and industries of the model.

\begin{tabular}{|c|c|c|c|c|}
\hline $\begin{array}{l}\text { Country } \\
\text { name }\end{array}$ & $\begin{array}{l}\text { Country } \\
\text { abbreviation }\end{array}$ & $\begin{array}{l}\text { Industry } \\
\text { name }\end{array}$ & $\begin{array}{l}\text { ISIC } \\
\text { code }\end{array}$ & $\begin{array}{l}\text { Industry } \\
\text { abbreviation }\end{array}$ \\
\hline Industrialized countries & & Traded goods & & \\
\hline Australia & ALA & Agr., for., \& fish. & 1 & Agric \\
\hline Austria & ATA & Food, bev., \& tob. & 310 & Food \\
\hline Canada & $\mathrm{CND}$ & Textiles & 321 & Text \\
\hline European Community & & Wearing apparel & 322 & Appar \\
\hline Belgium-Luxembourg & BLX & Leather products & 323 & Leath \\
\hline Denmark & DEN & Footware & 324 & Shoes \\
\hline France & FR & Wood products & 331 & Wood \\
\hline Germany & GFR & Furniture \& fixt. & 332 & Furn \\
\hline Ireland & IRE & Paper \& paper prod. & 341 & Paper \\
\hline Italy & IT & Printing \& publ. & 342 & Print \\
\hline The Netherlands & NL & Chemicals & $35 \mathrm{~A}$ & Chem \\
\hline United Kingdom & UK & Petrol. \& rel. prod. & $35 \mathrm{~B}$ & Petro \\
\hline Finland & FIN & Rubber products & 355 & Rubb \\
\hline Japan & JPN & Nonmetal. min. prod. & $36 \mathrm{~A}$ & Pott \\
\hline New Zealand & $\mathrm{NZ}$ & Glass \& glass prod. & 362 & Glass \\
\hline Norway & NOR & Iron \& steel & 371 & Iron \\
\hline Sweden & SWD & Nonferrous metals & 372 & Nonfe \\
\hline Switzerland & SWZ & Metal products & 381 & Metal \\
\hline United States & US & Nonelec. machinery & 382 & Mach \\
\hline Developing countries & & Elec. machinery & 383 & Elec \\
\hline Argentina & ARG & Transport equip. & 384 & Vehic \\
\hline Brazil & BRZ & Misc. manufact. & 38A & Other \\
\hline Chile & CHL & Non-traded goods & & \\
\hline Colombia & COL & Mining \& quarrying & 2 & Mine \\
\hline Greece & GRC & Elec., gas, \& water & 4 & Util \\
\hline Hong Kong & HK & Construction & 5 & Const \\
\hline India & IND & Whole. \& retail trade & 6 & W\&rtl \\
\hline Israel & ISR & Transp., stor., \& comm. & 7 & Trans \\
\hline South Korea & SK & Fin., insur., \& real est. & 8 & Finan \\
\hline Mexico & MEX & Comm., soc., \& pers. serv. & 9 & Serv \\
\hline Portugal & POR & & & \\
\hline Singapore & SNG & & & \\
\hline Spain & SP & & & \\
\hline Taiwan & TWN & & & \\
\hline Turkey & TRK & & & \\
\hline Yugoslavia & YUG & & & \\
\hline
\end{tabular}

An important feature of the model is its partial use of the Armington (1969) assumption that goods are differentiated by country of origin. This is a standard feature of computable trade models, making them consistent with empirical estimates of import elasticities and the fact that countries record

implausibly high in many countries. In that industry we have assumed instead that the dollar price is essentially fixed by a very large elasticity of supply with respect to that price for exports from the rest-of-world sector, while supplies within the included countries of the model are given an elasticity of near zero. 
both exports and imports in the same industry. In our implementation, demanders distinguish between imports and domestic goods, but not among imports from different sources abroad. Also, we assume separate domestic and export supply functions in each industry. These assumptions together capture much of the flavor of the full Armington assumption, without its computational complexity. However, as we will note below, our particular formulation may influence the size of the terms-of-trade effects that are generated by our model.

Regarding trade policies in the model, these appear in several forms. First we model tariffs as exogenous ad valorem taxes on imports. Second, another exogenous variable in each tradable industry can capture the change in a quantitative restriction on imports if the size of that change is known. Third, the model contains parameters to reflect the continued presence of quantitative restrictions in the various sectors when other changes occur in the model. These parameters are important for capturing the role that many NTBs play in reducing the price responsiveness of trade below what it would otherwise be. We have selected values for them in the DCs based primarily upon an inventory of quantitative restrictions in Murray and Walter (1978). Finally, lacking comprehensive data on quantitative restrictions in LDCs, we have for most purposes modeled them as using a system of import licensing to allocate scarce foreign exchange.

In the current application of the model, we wish to calculate the effects of the levels of protection reported in table 1 . Some of these data implicitly include quantitative restrictions, but they are measured as ad valorem equivalents and we have no information as to their direct quantitative effects. We therefore model all LDC protection as implemented by tariffs. We continue, however, to assume the presence of quantitative restrictions in the DCs.

\section{The neighborhood effects of protection}

To examine the neighborhood effects of protection, we did ten runs of the model. Nine were concerned with protection in each of the nine focus countries separately, while the tenth looked at protection in all nine simultaneously. In each case, the model was used, starting from a base of free trade in the LDCs, to calculate the effects of instituting the levels of protection reported in table 1 .

We wished to direct attention to the levels of protection themselves, and not factor in accidentally the effects of endogenous changes in disequilibrium exchange rates or exchange controls. We therefore ran the model under the assumption of perfectly flexible exchange rates in all the LDCs, even though this is manifestly inappropriate as a description of what have been the 
exchange regimes in most of these countries in recent years. ${ }^{15}$ On the other hand, to the extent that aspects of exchange rate management such as import licensing have introduced divergences between domestic and world prices in these countries, these divergences are taken into account in those of our data on protection that are labelled implicit tariffs. Thus to some extent our analysis includes the effects one might expect from a liberalization of exchange regimes. In any case, it seems better to make the assumption of a well functioning exchange market than to make the alternative assumption that protection can and would be permanently prevented from having its full general equilibrium effects.

These runs of the model produced a large amount of information about the effects of protection on various variables, both within the protecting countries and elsewhere. Most of this information is extraneous to our central purpose here, which is to consider the terms-of-trade effects of protection for each of the countries. This is of interest because, as explained above, it is primarily through the terms of trade that protection in one country can affect welfare in another. We do not report results for welfare per se, since certain aspects of our model make meaningful welfare calculations difficult, but we will conclude with some discussion of how complete welfare effects would differ from those indicated by the terms of trade alone.

Table 5, then, reports effects on the terms of trade. Each column refers to a different run of the model, in which protection is installed in the country indicated at the top of the column. The column headed 'All' reports the effects of adding protection in all nine focus countries at once. The rows contain effects on the terms of trade of the countries listed at the left. These are calculated, from the solution of the model, as the change in an index of world prices weighted by each country's exports, minus the change in such an index weighted by its imports. The numbers reported are in percentage terms, and are very small. Most interesting are their signs, which indicate whether neighborhood effects are positive or negative. In addition, their relative sizes allow comparison of own-country versus cross-country effects and the effects of individual country protection versus that of all nine focus countries together.

The top portion of table 5 reports effects of focus country protection on the focus countries themselves. Thus the diagonal of this portion of the table indicates the terms-of-trade effect of each country's own protection, and as one would expect these values are all positive.

The off-diagonal elements of this portion of the table are the neighborhood effects among the focus countries alone. These tend to be positive, but are not positive in every case. While the terms-of-trade effects of protection by

\footnotetext{
${ }^{15}$ Also, with flexible exchange rates, there is no need to use the system of import licensing that would otherwise operate in many of the LDCs of the model.
} 


\begin{tabular}{|c|c|c|c|}
\hline $\bar{z}$ & 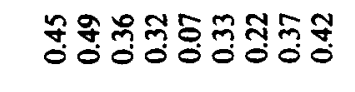 & 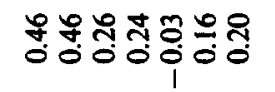 & 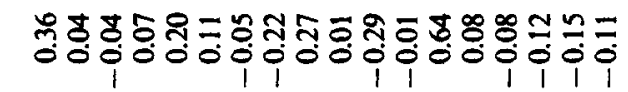 \\
\hline 并 & 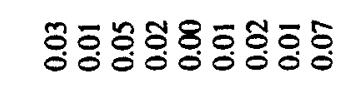 & 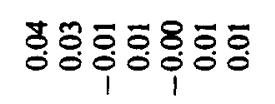 & 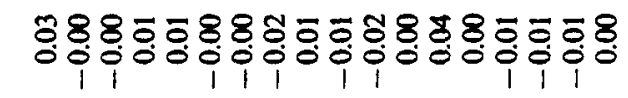 \\
\hline z & 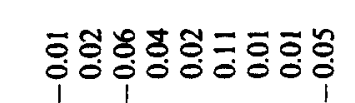 & 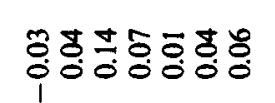 & 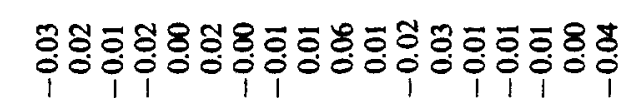 \\
\hline 产 & 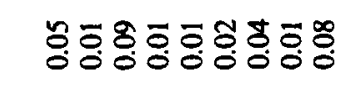 & : & 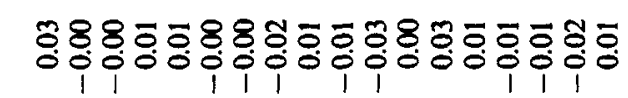 \\
\hline$\stackrel{2}{m}$ & 308080080 & 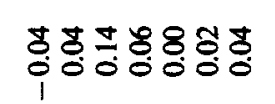 & 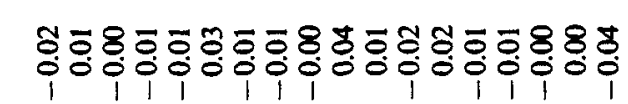 \\
\hline$\underline{\underline{w}}$ & 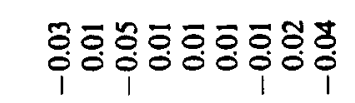 & togen & 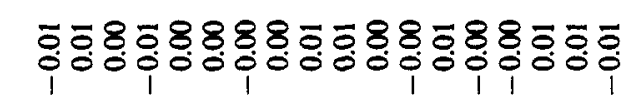 \\
\hline 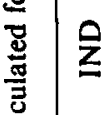 & 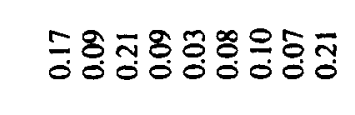 & $\overline{2} \div \pm 0.00$ & 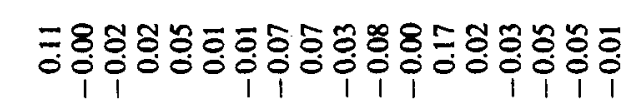 \\
\hline $\overrightarrow{8}$ & 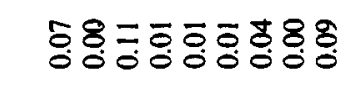 & 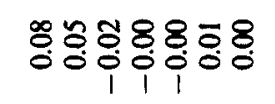 & 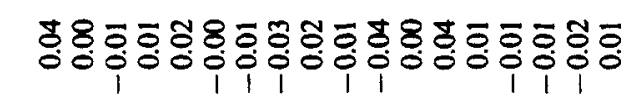 \\
\hline $\overrightarrow{\underline{I}}$ & 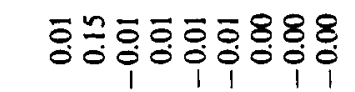 & s:ob & 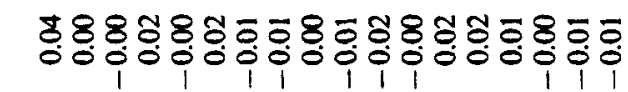 \\
\hline$\frac{N}{x}$ & 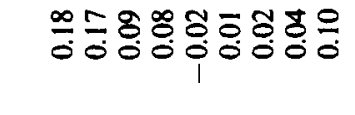 & 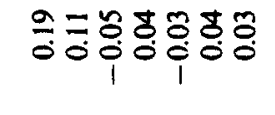 & 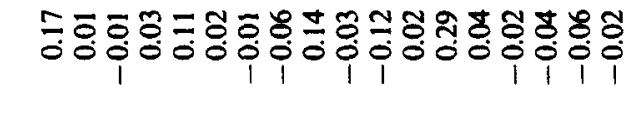 \\
\hline & 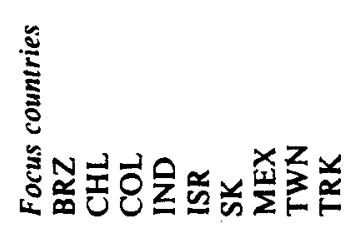 & 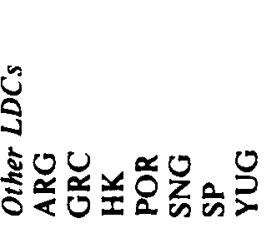 & 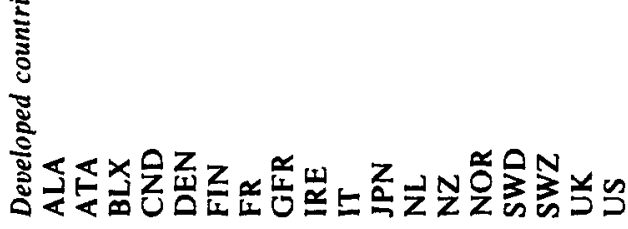 \\
\hline
\end{tabular}


Brazil, Colombia, India, Mexico, and Turkey are almost all positive for the other focus countries, protection by Chile, Israel, South Korea and Taiwan has negative effects in a number of cases. By and large these neighborhood effects tend to be positive, but not uniformly so.

These results extend for the most part to the other LDCs of the model, as shown somewhat further down in the table, but they are reversed, as one would expect, for the DCs. There are a great many negative terms-of-trade effects reported for the DCs.

Taken as a group in the last column of table 5 , protection by all the focus countries together improves the terms of trade of each of them. This improvement extends to all other LDCs as well except for Singapore, whose terms-of-trade deterioration seems to result almost exclusively from protection in Brazil. Even several DCs experience terms-of-trade improvement as a result of the collective focus-country protection, but the terms of trade of the largest developed countries - France, Germany, Japan, the U.K. and the U.S. - respond negatively.

Thus we conclude that protection in each of several LDCs, as reflected in the particular data from the 1960s that we had available, does tend to be reinforcing. That is, these countries achieve a modest improvement in their terms of trade as a result of this protection, at the expense, evidently, of their largest DC trading partners.

This is important since it means that terms-of-trade improvement, which is the one clear economic benefit that can be derived from protection in traditional analysis of trade theory, is not being undermined in the LDCs by the effects of their protection on each other. ${ }^{16}$ We should stress, however, that this does not mean that the overall effects of protection are desirable for these countries. We have reported only the terms-of-trade effects here, and it is likely that the other adverse effects of protection would outweigh them.

These adverse effects all have to do with the protecting country itself, and are precisely the efficiency effects alluded to in section 2 . That is, protection causes domestic consumers and producers to face prices that are different from the terms of trade of the country itself, and thus distorts their decisions away from what would have been optimal given that terms of trade. The standard result of international trade theory is that these efficiency effects cause the net loss by producers and consumers due to protection to be larger than any revenue or rents that can be derived from that protection. Thus, aside from beneficial effects on the terms of trade, countries tend to lose by imposing protection.

In the cases examined here, the terms-of-trade improvement that can be obtained by protection in LDCs is extremely small, as one would expect

\footnotetext{
${ }^{16}$ For a critical discussion of other benefits that have been suggested as arising from protection, see Deardorff and Stern (1985a).
} 
from the small role that each of these countries plays in world markets. In these circumstances it is almost inevitable that the adverse efficiency effects of protection are larger than the terms-of-trade improvement.

There are some qualifications to this that should perhaps be mentioned, however. First, the standard analysis of the welfare effects of protection assumes balanced trade, and this is not a valid assumption for the countries looked at here. While it is not clear how analysis of welfare should be modified in the presence of unbalanced trade, some preliminary calculations that we have done with our model suggest that these trade imbalances may be somewhat important.

A second qualification relates to a feature of our model that is not shared by some other computable trade models and that seems to be important in determining terms-of-trade effects. As noted in section 5, in our partial implementation of the Armington assumption buyers do not distinguish among imports from different countries. Other models, such as Whalley (1984) and Brown (1984), have incorporated the full Armington assumption and have tended to find larger terms-of-trade effects than we typically find with our model.

Brown (1984) has argued that the reason for this difference is that, in our model, exporters compete with all other exporters of the same good while, with the full Armington assumption, each country's exporters have a market of their own. We agree with this assessment and recognize therefore that our terms-of-trade effects might be underestimates. On the other hand, lacking information on elasticities of substitution between imported goods from different sources, we are not convinced that the complete Armington formulation, if used without differentiating these elasticities, is preferable to our own. It seems unlikely, especially, that small LDCs are able to differentiate their products sufficiently to acquire much influence over their terms of trade.

\section{Conclusion}

In this paper we have looked at how protection in LDCs affects welfare in other countries, particularly their economic neighbors, the other LDCs. We found first in theoretical terms that the answer could go either way, depending on whether the countries share similar structures of trade and protection. Thus the question is an empirical one, and we were led to base our analysis on a sample of data on protection in nine LDCs.

The data themselves offered conflicting messages concerning this issue. On the one hand, there were generally positive correlations among patterns of protection in the various countries for which we had data, and we found even stronger positive correlations for the data on trade. However, when we combined the data on protection and trade to see how they match up, we 
found a tendency for the focus countries to protect more heavily against the exports of other LDCs than against DC exports.

We therefore used the Michigan model of world production and trade to do a more careful calculation of what this protection implies for the terms of trade of the countries of the world. We found that protection by our focus countries tended to have positive terms-of-trade effects on other countries within the group, and negative effects for many DCs. That is, there was some tendency for the neighborhood effects of these countries' protection to be positive. This effect is very small, however, and cannot be expected to outweigh the efficiency losses that protection entails within the LDCs themselves.

\section{References}

Armington, Paul S., 1969, A theory of demand for products distinguished by place of production, International Monetary Fund Staff Papers 16, 159-178.

Behrman, Jere R., 1976, Foreign trade regimes and economic development: Chile (Columbia University Press, New York).

Bergsman, Joel, 1970, Brazil: Industrialization and trade policies (Oxford University Press, New York).

Bhagwati, Jagdish N. and .T.N. Srinivasan, 1975, Foreign trade regimes and economic development: India (Columbia University Press, New York).

Brown, Drusilla, 1984, A simulation model of world production and trade with bilateral trade and commercial policies and application to the Tokyo Round, Ph.D dissertation (The University of Michigan, Ann Arbor, MI).

Deardorff, Alan V., 1979, Weak links in the chain of comparative advantage, Journal of International Economics 9, 197-209.

Deardorff, Alan V. and Robert M. Stern, 1981, A disaggregated model of world production and trade, Journal of Policy Modeling 3, 127-152.

Deardorff, Alan V. and Robert M. Stern, 1985a, Current issues in U.S. trade policies: An overview, in: Robert M. Stern, ed., U.S. trade policies in a changing world economy (MIT Press, Cambridge, MA) forthcoming.

Deardorff, Alan V. and Robert M. Stern, 1985b, Input-output technologies and the effects of tariff reductions, Journal of Policy Modeling 7, 253-279.

Deardorff, Alan V. and Robert M. Stern, 1985c, Methods of measurement of nontariff barriers, UNCTAD/ST/MD/28 (Geneva).

Deardorfi, Alan V. and Robert M. Stern, 1986, The Michigan model of world production and trade: Theory and applications (M.I.T. Press, Cambridge, MA).

Frank, Charles R., Kwang Suk Kim and Larry Westphal, 1975, Foreign trade regimes and economic development: South Korea (Columbia University Press, New York).

Hsing Mo-Huan, 1971, Taiwan: Industrialization and trade policies (Oxford University Press, New York).

King, Timothy, 1970, Mexico: Industrialization and trade policies since 1940 (Oxford University Press, New York).

Krueger, Anne O., 1974, Foreign trade regimes and economic development: Turkey (Columbia University Press, New York).

Krueger, Anne O., 1977, Growth, distortions, and patterns of trade among many countries, Princeton Studies in International Finance, no. 40 (Princeton University, Princeton, NJ).

Michaely, Michael, 1975, Foreign trade regimes and economic development: Israel (Columbia University Press, New York). 
Murray, Tracy and Ingo Walter, 1978, Special and differential liberalization of quantitative restrictions on imports from developing countries, in: L. Perez, ed., Trade policies towards developing countries: The multilateral trade negotiations (Agency for International Development, Washington, DC).

Thoumi, Francisco E., 1981, International trade strategies, employment, and income distribution in Colombia, in: Anne O. Kruger et al., eds., Trade and employment in developing countries, Vol. 1, Individual studies (University of Chicago Press, Chicago, IL).

Whalley, John, 1984, Trade liberalization among major world trading areas (MIT Press, Cambridge, MA). 